\title{
ANALYSIS OF THE RELATIONSHIP BETWEEN SOCIAL INDICATORS AND MORTALITY FOR BREAST CANCER IN BRAZIL AND GOIÁS
}

Silvaleide Ataides Assunção', Ana Carla Moreira Miranda', Laura Queiroz da Silva', Mariana Campos Terra', Guilherme Augusto da Costa', Anelize Maria Bunholli', Rosemar Macedo Sousa Rahal²

${ }^{1}$ Faculdade de Medicina, Universidade Federal de Goiás - Goiânia (GO), Brazil.

${ }^{2}$ Hospital das Clínicas, Universidade Federal de Goiás - Goiânia (GO), Brazil.

Objectives: Breast cancer is the most common cancer among the female population in the world. Socioeconomic and cultural factors are important, as underdeveloped countries have high mortality rates due to deficiencies in prevention and early detection. Thus, the objective is to verify whether there is a direct relationship between the number of deaths due to breast cancer and social indicators. Methodology: A descriptive study with the analysis of the secondary data on mortality from malignant breast neoplasms, relating them to social indicators of schooling, age, and color/race between the years 2010 and 2019 in the state of Goiás and in Brazil, was analyzed. The data were extracted from the Mortality Information System (SIM), ordered, and tabulated using Excel. Results: Socioeconomic factors, such as education, age group, race, and geographic region, were considered conditioning factors for inequalities for such neoplasia. Groups with lower socioeconomic status showed high mortality rates, either due to later diagnoses or due to greater difficulty in accessing appropriate treatments. In contrast, the population inserted in favored socioeconomic scenarios presented, at the same time, high mortality rates, not only in Goiás, but also in the Brazilian scenario in general. This situation resulted, above all, from the insertion of this female portion in the labor market and, consequently, from the acquisition of new habits and behaviors. Conclusion: Different variables related to socioeconomic and cultural conditions have a direct influence on the occurrence of breast cancer in women in the state of Goiás and also in Brazil. In summary, people in disadvantaged situations tend to have high mortality rates for not having access to financing health conditions, while the wealthier population also has high rates due to cultural factors and related to new habits and behaviors that are factors risk.

Keywords: Breast Cancer; Social Indicators; Inequalities. 